\title{
Porous Polylactic Acid-Silica Hybrids: Preparation, Characterization, and Study of Mesenchymal Stem Cell Osteogenic Differentiation
}

\author{
Christos Pandis, * Sara Trujillo, Joana Matos, Sara Madeira, \\ Joaquín Ródenas-Rochina, Sotiria Kripotou, Apostolos Kyritsis, \\ João F. Mano, José Luis Gómez Ribelles
}

A novel approach to reinforce polymer porous membranes is presented. In the prepared hybrid materials, the inorganic phase of silica is synthesized in-situ and inside the pores of aminolyzed polylactic acid (PLA) membranes by sol-gel reactions using tetraethylorthosilicate (TEOS) and glycidoxypropyltrimethoxysilane (GPTMS) as organic

inorganic

hybrid precursors. The hybrid materials present a porous structure with a silica layer covering the walls of the pores while GPTMS serves also as coupling agent between the organic and inorganic phase. The adjustment of silica precursors ratio allows the modulation of the thermomechanical properties. Culture of mesenchymal stem cells on these supports in osteogenic medium shows the expression of characteristic osteoblastic markers and the

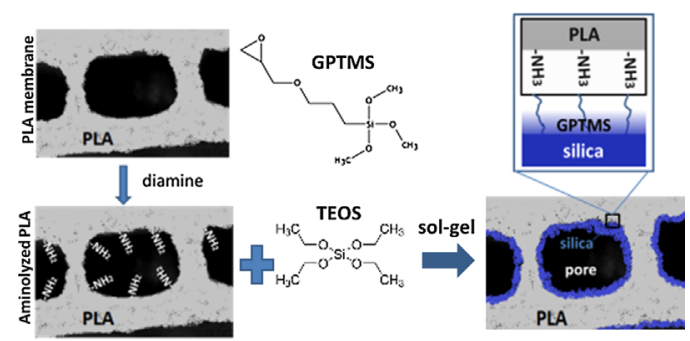
mineralization of the extracellular matrix.

Dr. C. Pandis, Dr. S. Kripotou, Prof. A. Kyritsis

Physics Department, National Technical University of Athens,

Zografou Campus, Athens 15780, Greece

E-mail: pandis@mail.ntua.gr

Dr. C. Pandis, S. Trujillo, J. Ródenas-Rochina,

Prof. J. L. Gómez Ribelles

Centro de Biomateriales e Ingeniería Tisular, Universitat

Politècnica de València, Camino de Vera s/n, Valencia 46022, Spain

J. Matos, S. Madeira, Prof. J. F. Mano

3B's Research Group - Biomaterials, Biodegradables and

Biomimetics, University of Minho, Headquarters of the European Institute of Excellence on Tissue Engineering and Regenerative Medicine, AvePark, Taipas, Guimarães 4806-909, Portugal

Prof. J. F. Mano

ICVS/3B's - PT Government Associate Laboratory, Braga/Guimarães, Portugal

Prof. J. L. Gómez Ribelles

Ciber en Bioingeniería, Biomateriales y Nanomedicina (CIBER-BBN),

Valencia, Spain

\section{Introduction}

Poly(lactic acid) (PLA) is a linear aliphatic polyester obtained from renewable resources such as corn starch and sugar. ${ }^{[1]}$ It is a semicrystalline, degradable thermoplastic polymer presenting good biocompatibility and low toxicity. ${ }^{[2]}$ The above characteristics of PLA combined with its good processability have attracted an increasing interest for use in many applications in the biomedical field including scaffolding for bone and cartilage tissue engineering ${ }^{[3]}$ For many of the above applications, the mechanical properties of pure PLA need to be improved as well as the degradation and biocompatibility characteristics. To that end, the structural unit, lactic acid, is often used for the synthesis of copolymers for example poly(lactide-co-glycolide) (PLGA), ${ }^{[4]}$ with tailorable biodegradation while surface modification can improve hydrophilicity and affinity with cells. ${ }^{[5]}$ Among the various physical and chemical 
methods, the surface modification using diamines, known as aminolysis, is a very efficient wet chemical route for introducing amino and hydroxyl groups in the surface of polyesters. ${ }^{[6]}$ Furthermore, blending with other polymers ${ }^{[7]}$ or mixing with inorganic particles ${ }^{[8]}$ in order to produce composites appears as an appealing route for tailoring its properties. Various inorganic materials has been used for the production of composites having PLA as the matrix such as nano-hydroxyapatite HAp, ${ }^{[9]}$ layer silicates, ${ }^{[10]}$ carbon nanotubes $(\mathrm{CNT}),{ }^{[11]}$ bioglass, ${ }^{[12]}$ or silica nanoparticles. ${ }^{[13,14]}$

All the above approaches are based on the incorporation of the inorganic phase as a filler in the form of micro or nanoparticles inside the polymer matrix. In this work, a different strategy for the production of hybrid organicinorganic composite was followed: The inorganic silica phase was synthesized in situ inside the pores of already prepared PLA membranes. To that aim, the versatile method of sol-gel method was employed using TEOS and GPTMS as the silica precursors. The sol-gel reactions were performed in acidic conditions in order to produce a continuous silica phase covering the pore walls of the membranes. ${ }^{[15,16]}$ The silica network was produced after the hydrolysis and condensation of TEOS and GPTMS. The latter also has an epoxy ring to one end permitting to link with functionalized PLA and thus can serve as coupling agent between the silica and the PLA phase. In order to enhance the affinity with PLA, its surface was functionalized by introducing amino groups. The hypothesis is that GPTMS can act as a bridge between the silica network and the aminolyzed PLA through the reaction of the epoxy ring with the free amino groups introduced in the polymer. Porous membranes with various TEOS/GPTMS ratios were fabricated and the steps of the preparation procedure were assessed by various techniques. The morphology, water sorption behavior, thermal, and mechanical properties of the prepared hybrid membranes were studied and discussed. Culture of mesenchymal stem cells on these supports in osteogenic medium shows the expression of characteristic osteoblastic markers and the mineralization of the extracellular matrix. Furthermore, the proliferation and osteoblastic differentiation potential was studied using porcine bone marrow mesenchymal stem cells.

\section{Experimental Section}

\subsection{PLA Membranes Preparation and Functionalization}

PLA porous membranes were prepared by the freeze extraction method: ${ }^{[17]}$ PLA (Natureworks Ingeo 4042D) was dissolved in dioxane (99\%, Scharlau) to prepare a solution of $10 \% \mathrm{w} / \mathrm{w}$. After stirring for $24 \mathrm{~h}$, the solution was poured in Teflon molds, frozen with liquid nitrogen and put at $-20^{\circ} \mathrm{C}$. Already frozen ethanol at $-20^{\circ} \mathrm{C}$ was used to fully cover the membranes and being changed for at least three times during $48 \mathrm{~h}$ in order to remove the solvent. The membranes were left at room temperature for $24 \mathrm{~h}$ and vacuum dried at $40{ }^{\circ} \mathrm{C}$ for $24 \mathrm{~h}$ before further treatment. Furthermore, PLA films were prepared by solvent casting.

The introduction of amino groups in the surface of already prepared PLA films and membranes was performed by an aminolysis reaction using 1,6-hexanediamine (Acros Organics). Preliminary tests varying reaction time, temperature, and concentration were performed and finally a mild procedure described in ref. ${ }^{[18]}$ was chosen: the membranes were immersed in a solution of 1,6-hexanediamine in isopropanol (Scharlau) with a concentration of $10 \mathrm{mg} \mathrm{ml}^{-1}$ at $58^{\circ} \mathrm{C}$ for $1 \mathrm{~min} 30 \mathrm{~s}$. In order to remove any unreacted species, the membranes were rinsed with distilled water and left in a solution of isopropanol/water 1:1 for $24 \mathrm{~h}$ changing it two times. Finally, the aminolyzed membranes were vacuum dried at $40^{\circ} \mathrm{C}$ for $24 \mathrm{~h}$.

\subsection{Introduction of Silica Phase Inside the Membrane Pores}

Sol-gel method was used for the introduction of the silica phase inside the pores of the already prepared membranes. Silica precursor was a mixture of tetraethyl orthosilicate (TEOS) (Sigma-Aldrich) and 3-glycidoxypropyltrimethoxysilane (GPTMS) (Sigma-Aldrich). The molar ratio of GPTMS with respect to TEOS in the sol-gel solution was varied between 0.05 to 1 , while the molar ratios of the rest components, with respect to TEOS as well, (water, ethanol, and chloride acid) of the starting solution were kept constant $(1,2$, and 0.0185 , respectively). After $1 \mathrm{~h}$ of stirring, the above solution was transferred to a glass tube allowing to fully cover the PLA membranes. In order to assure that the pores of the polymer be filled by the prepared solution, a vacuum pump attached to the reaction tube was used prior to the introduction of the solution. After $15 \mathrm{~min}$, the samples were removed from the solution, and superficially rinsed with water:ethanol $2: 1 \mathrm{v} / \mathrm{v}$ solution. The membranes were left at room temperature for $24 \mathrm{~h}$ and then heated to $90^{\circ} \mathrm{C}$ for $24 \mathrm{~h}$. Finally, the samples after the completion of sol-gel reactions were washed with distilled water to remove any unreacted species.

\subsection{Morphology Characterization}

The morphology of the PLA and PLA/silica membranes was studied by means of scanning electron microscopy (SEM) in a JSM-6300 microscope (JEOL) using an accelerating voltage of $10 \mathrm{kV}$ with the samples previously sputter coated with gold. The cross-section visualization of the samples was done after being cryofractured using liquid nitrogen.

Porosity was measured by a gravimetric method. Firstly, the dried samples were weighed before and after being immersed in ethanol. Porosity, $p(\%)$, was calculated as the quotient of the volume of pores $\left(V_{\text {pore }}\right)$ and the total volume of the membrane ( $\left.V_{\text {total }}\right)$.

The volume occupied by pores, $V_{\text {pores }}$, was deduced from the weight difference between dry $\left(m_{\text {dry }}\right)$ and wet $\left(m_{\text {wet }}\right)$ sample,

$$
p(\%)=\frac{V_{\text {pores }}}{V_{\text {Total }}}=\frac{V_{\text {pores }}}{V_{\text {polym }}+V_{\text {pores }}} \times 100
$$


The volume of the polymer, $V_{\text {polym }}$, and of the pores, $V_{\text {pores }}$, was calculated using the density of ethanol $\left(\rho_{\text {ethanol }}=0.79 \mathrm{~g} \mathrm{~cm}^{-3}\right)$ and of PLA $\left(\rho_{\text {PLA }}=1.25 \mathrm{~g} \mathrm{~cm}^{-1}\right)$.

\subsection{Gel Permeation Chromatography (GPC) and Fourier Transform IR Analysis}

Molecular weight distribution for membranes of different aminolysis time was studied using a chromatograph Waters 1525 fitted with a Binary HPLC pump, Waters ${ }^{\mathbb{R}} 2414$ refractive index detector and four serial columns Styragel HR 5 THF, Styragel HR 4 THF, Styragel 1 THF, Styragel HR 0.5 THF, using tetrahydrofuran (THF) as mobile phase. The flow rate was $1.0 \mathrm{ml} \mathrm{min}^{-1}$ and the samples were prepared with $5 \% \mathrm{w} / \mathrm{v}$ in THF. The concept of universal calibration was used to estimate the molecular weight of pure PLA and PLA aminolyzed using monodisperse polystyrene (PS) standards SM105 (Showa Denko) according to the procedure reported in ref., ${ }^{[19]}$ using $\mathrm{K}_{\mathrm{PLA}}=5.45 \times 10^{-5} \mathrm{dL} \mathrm{g}^{-1}$ and $\mathrm{a}_{\mathrm{PLA}}=0.73$ as the MarkHouwink-Sakurada parameters for PLA ${ }^{[20]}$ and $K_{P S}=1.14 \times 10^{-4} \mathrm{dL}$ $\mathrm{g}^{-1}$ and $\mathrm{aPS}_{\mathrm{PS}}=0.716$ for PS. More details on the calculation procedure could be found in ref. ${ }^{[21]}$

Fourier-transform infrared (FTIR) spectra were collected in a Thermo Nicolet Nexus FTIR spectrometer (Thermo Fischer Scientific, Inc., Waltham, MA, USA), in the attenuated total reflection mode (ATR). The spectra resulted from averages of 128 scans at $4 \mathrm{~cm}^{-1}$ resolution, between 650 and $4000 \mathrm{~cm}^{-1}$.

\subsection{Thermomechanical Characterization}

The thermal properties of samples were studied by thermogravimetric analysis (TGA) using a SDT-0600 (TA-Instruments) equipment in nitrogen atmosphere with a constant heating rate of $10^{\circ} \mathrm{C} \mathrm{min}^{-1}$ from room temperature to $650^{\circ} \mathrm{C}$.

Differential scanning calorimetry (DSC) measurements were performed using a Pyris 1 apparatus (Mettler Toledo). In order to erase the effects of any previous thermal history, the samples were heated to $180^{\circ} \mathrm{C}$ and then subjected to a cooling scan down to $0^{\circ} \mathrm{C}$ at $20^{\circ} \mathrm{C} \mathrm{min}^{-1}$, followed by a heating scan up to $180^{\circ} \mathrm{C}$ at a rate of $10^{\circ} \mathrm{C} \mathrm{min}^{-1}$.

\subsection{Water Vapor Sorption}

Water vapor adsorption experiments were performed using a VTI$\mathrm{SA}+$ (TA Instruments) vapor sorption analyzer at $25^{\circ} \mathrm{C}$. The equilibrium water vapor sorption isotherms were obtained for water activities up to 0.95 .

\subsection{Cell Culture Studies}

\subsubsection{Cell Harvesting and Subculturing}

Primary cell culture mesenchymal stem cells was obtained from pig bone marrow. Femur from four-month-old porcine donor was fleshless, disinfected with $70 \%$ ethanol and sawn the femora upper part. Gelatinous bone marrow was removed from medullary cavity washed with culture medium (Dulbecco's modified Eagle's medium (DMEM; 10938025, Fisher), 1\% Pen/Strp ((10000 units $\mathrm{ml}^{-1}$ penicillin, $10000 \mu \mathrm{g} \mathrm{ml}^{-1}$ streptomycine), D17-602E, Lonza), $10 \%$ fetal bovine serum HyClone (FBS, SH30071.03, Fisher), and 10\% GlutaMAX (61965, Gibco)) and triturated with a syringe with 16 -gauge needle. Sample was homogenized, centrifuged at $650 \mathrm{~g}$ for 5 min and supernatant was discarded. Sample was resuspended and centrifuged again before to filter using a $40 \mu \mathrm{m}$ nylon filter. Finally, cells were seeded in T75 flasks at a density of $10 \times 10^{6}$ cells/flask. Bone marrow mesenchymal stem cells (BM-MSCs) were expanded until passage 2 using expansion medium (Xpan) (DMEM, 1\% Pen/ Strp, 10\% FBS, 10\% GlutaMAX, $5 \mathrm{ng} \mathrm{ml}^{-1}$ fibroblast growth factor-2 (FGF-2, PCYT-218, Eurobio) in $75 \mathrm{~cm}^{2}$ cell culture flasks at $37^{\circ} \mathrm{C}$, $5 \% \mathrm{CO}_{2}$ and $95 \%$ humidity.

Mycoplasma test (MycoAlert ${ }^{\mathrm{TM}}$ Plus Mycoplasma Detection Kit, Lonza) was performed before each culture according to the manufacturer's guideline. Briefly, $1.5 \mathrm{ml}$ of $24 \mathrm{~h}$ culture supernatant was centrifuged and $100 \mu \mathrm{l}$ were transfer into a 96-well-plate. Then, $100 \mu$ l of MycoAlert ${ }^{\text {TM }}$ Plus Reagent were added and incubated $5 \mathrm{~min}$ at RT, samples were read (reading A). Finally, $100 \mu$ l of MycoAlert ${ }^{\mathrm{TM}}$ Plus Substrate were added to each sample, incubated for $10 \mathrm{~min}$ at RT and samples were read (reading B). Ratio of reading B/reading A was calculated. Ratios below 1 were negative for mycoplasma.

\subsubsection{Differentiation Study}

Differentiation study culture was performed in $5 \mathrm{~mm}$ diameter samples at 1, 7, 14, and $21 \mathrm{~d}$. Samples sterilized with gamma ray radiation (25kGy performed by Aragogamma) were washed in Dulbecco's phosphate buffer saline (DPBS; D5652 Sigma) and incubated with Xpan medium for $1 \mathrm{~h}$ at $37^{\circ} \mathrm{C}, 5 \% \mathrm{CO}_{2}$ and $95 \%$ humidity. Samples were deposited in 3\% agarose coated 96multiwell plate seeded at a density of 51000 cells $\mathrm{cm}^{-2}$ in Xpan medium. After $24 \mathrm{~h}$ of cell seeding, culture medium was changed with osteogenic differentiation medium (DMEM; 1\% Pen/Strp, 10\% FBS, $0.31 \times 10^{-5}$ M dexamethasone (D2915 Sigma), $0.05 \mathrm{~mm}$ ascorbic acid (A4403 Sigma) and 1 м $\beta$-glycerol phosphate (50020 Sigma)). Samples were previously conditioned in DMEM for $24 \mathrm{~h}$ at $37^{\circ} \mathrm{C}$, $5 \% \mathrm{CO}_{2}$ and $95 \%$ humidity.

\subsubsection{DNA and Collagen Measurement}

Samples were removed at 1, 7, 14, and $21 \mathrm{~d}$ and washed with DPBS and stored at $-80^{\circ} \mathrm{C}$ until the analysis was performed. After thawing, cells were digested adding papain (Sigma) at $161 \mu \mathrm{g} \mathrm{ml}^{-1}$ dissolved in activation buffer (63 $\mathrm{mg}$ of L-cysteine hydrochloride hydrate (c7477, Sigma) in $40 \mathrm{ml}$ of papain buffer extraction (PBE; $100 \mathrm{ml}$ milio water, $0.653 \mathrm{~g} \mathrm{Na}_{2} \mathrm{HPO}_{4}$ (S3264, Sigma), $0.648 \mathrm{~g}$ $\mathrm{NaH}_{2} \mathrm{PO}_{4}$ (S3139, Sigma), $1 \mathrm{ml}$ of ethylenediaminetetraacetic acid $500 \mathrm{~mm}$ (EDTA; 15575020, Invitrogen), pH 6.5)) to solubilize the biomolecules and protect it from enzymes released from lysed cells. Samples were incubated for $18 \mathrm{~h}$ at $60^{\circ} \mathrm{C}$ in the hotbox at $10 \mathrm{rpm}$. Digested samples were used immediately for DNA quantification assays, and they were stored at $-80^{\circ} \mathrm{C}$ until collagen quantification assay.

DNA content was performed with Quant-iT ${ }^{\mathrm{TM}}$ PicoGreen ${ }^{\circledR}$ dsDNA Kit (Invitrogen) according to the manufacturer's guideline. Briefly, $28.7 \mu$ l of digested samples and standards were placed into black 96-well-plate, $71.3 \mu$ l of Picogreen Solution 1:200 in TE buffer

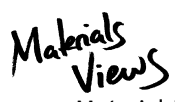

www.MaterialsViews.com
Macromol. Biosci. 2014, DOI: 10.1002/mabi.201400339

(C) 2014 WILEY-VCH Verlag GmbH \& Co. KGaA, Weinheim

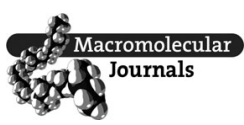


and $100 \mu$ l of $1 \times$ Tris-EDTA buffer (TE). Samples were incubated 5 min minimal light conditions. Samples were read in a Victor3 microplate reader (Perkin Elmer) at $480 \mathrm{~nm}$ excitation and $520 \mathrm{~nm}$ emission. Standard curve was constructed using a commercial digested DNA.

Total collagen quantification was performed by means of hydroxylation of hydroxyproline. ${ }^{[22,23]}$ Digested sample at 7, 14, and $21 \mathrm{~d}$ was mixed with the same volume of $37 \% \mathrm{HCl}$ and incubated for $18 \mathrm{~h}$ at $110^{\circ} \mathrm{C}$. Samples were cooled centrifuged at 5 $000 \mathrm{~g}$ for $5 \mathrm{~min}$. Then, samples were dried at $45^{\circ} \mathrm{C}$ for $2-3 \mathrm{~d}$ and were resuspended in $200 \mu \mathrm{l}$ of milio water. Samples were centrifuged and supernatant was immediately analyzed. Assays were performed in 96-well-plates adding $60 \mu \mathrm{l}$ in triplicate of each sample and control, $20 \mu \mathrm{l}$ of assay buffer (1.5 ml n-propanol (402893, Sigma), $1 \mathrm{ml}$ milio water, $5 \mathrm{ml}$ citrate stock buffer $(80 \mathrm{ml}$ milio water, $5.04 \mathrm{~g}$ citric acid monohydrated (c1909, Sigma), $11.98 \mathrm{~g}$ sodium acetate trihydrate (S7670, Sigma), $7.22 \mathrm{~g}$ anhydrous sodium acetate (S2889, Sigma), $3.2 \mathrm{~g} \mathrm{NaOH}$ (655104, Sigma), $1.26 \mathrm{ml}$ glacial acetic acid (695084, Sigma), $\mathrm{pH} 6.1)$ ) and $40 \mu \mathrm{l}$ of Chloramine- $T$ reagent (141 mg Chloramine-T (857319, Sigma), $500 \mu$ l milio water, $500 \mu \mathrm{l} n$-propanol, $4 \mathrm{ml}$ citrate stock buffer). Plates were covered with tinfoil and incubated for $20 \mathrm{~min}$ at RT to allow hydroxyproline oxidation to complete. Then, $80 \mu$ l of DMBA reagent $(6 \mathrm{ml} \mathrm{n}$ propanol, $3 \mathrm{ml} 70 \%$ perchloric acid (244252, Sigma), $4.5 \mathrm{~g} \mathrm{4-}$ (dimethylamino)benzaldehyde (39070, Sigma)) was added. Plates were covered with sealplate film and incubated at $60^{\circ} \mathrm{C}$ for $20 \mathrm{~min}$. After cooling, plates were read at $570 \mathrm{~nm}$ in a plate spectrophotometer VICTOR3 from Perkin Elmer. Standard curve of known concentrations of $50 \mu \mathrm{g} \mathrm{ml}^{-1}$ of cis-4-hydroxyproline (56246, Sigma) in PBE stock solution was used.

\subsubsection{Alkaline Phosphatase Activity Quantification}

The ALP activity was measured as the conversion of $p$-nitrophenylphosphate into $p$-nitrophenol. Samples of $21 \mathrm{~d}$ were placed on eppendorfs with $100 \mu$ l of lysis buffer (2\% Triton X-100 (T9284 Sigma), $10 \mathrm{~mm}$ Tris- $\mathrm{HCl}\left(\mathrm{C}_{4} \mathrm{H}_{11} \mathrm{NO}_{3} \cdot \mathrm{HCl}, 93314\right.$ Sigma), pH 7.2) and incubated $10 \mathrm{~min}$ on ice and finally sonicated for $2 \mathrm{~min}$. After that, samples were centrifuged and supernatants were added into new eppendorfs. Supernatants were incubated for $2 \mathrm{~h}$ at $37^{\circ} \mathrm{C}$ with p-nitrophenylphosphate ( $1 \mathrm{mg} \mathrm{ml}^{-1}$ (71770 Fluka) dissolved in substrate buffer (50 mM glycine, $1 \mathrm{mM} \mathrm{MgCl}_{2^{*}}\left(\mathrm{H}_{2} \mathrm{O}\right)_{6}, \mathrm{pH}$ 10.5)) on minimal light conditions and the reaction was stopped with $50 \mu \mathrm{l}$ $\mathrm{NaOH} 1 \mathrm{~m}$. One hundred microliters of each sample was added in triplicate into a 96-well-plate and were read at $405 \mathrm{~nm}$ with a plate spectrophotometer (VICTOR3, Perkin Elmer). Dilutions of $p$-nitrophenol (N7660 Sigma) in NaOH $0.02 \mathrm{M}$ at various known concentrations were used to construct the standard curve.

\subsubsection{Histochemical Staining}

Alizarin red staining was assessed to detect calcium precipitates. Briefly, samples were washed with DPBS and then they were immersed in chilled absolute ethanol for $10 \mathrm{~min}$ at RT. After that, samples were rinsed with DPBS and then with water. Alizarin RedS solution (1\% Alizarin RedS (A5533, Sigma) in water, pH 4.1) was added for $1 \mathrm{~min}$ at RT and finally, samples were washed gently with water and the staining was fixed with absolute ethanol.
Picrosirius red staining was performed to detect collagen upon samples. Briefly, samples were washed with distilled water for $10 \mathrm{~min}$ and then they were immersed in Pricrosirius red solution ( $0.5 \mathrm{~g}$ Direct Red 80 (365548, Sigma) in $500 \mathrm{ml}$ of saturated aqueous solution of picric acid) for $25 \mathrm{~s}$. Then samples were immersed in $0.5 \%$ acetic acid solution for $30 \mathrm{~s}$ and distilled water for $30 \mathrm{~s}$. Finally, a counterstaining with hematoxylin for $30 \mathrm{~s}$ washing with water was performed. Samples were mounted with $85 \%$ glycerol in water.

\section{Results and Discussion}

\subsection{Aminolysis of PLA Membranes}

The first step of the preparation procedure was the fabrication of porous PLA membranes and their functionalization with free amino groups in order to be able to react later with GPTMS. A diamine, 1,6-hexanediamine, was used for that purpose as has been proposed by other authors. ${ }^{[18,24]}$ The concentration of the diamine, the temperature, and the time of the aminolysis reaction influence the final concentration of the amino groups in the functionalized surfaces. As it is well known for such reactions in polyesters, the aminolysis involves the chain scission of the polymer backbone that leads to lowering of the molecular weight and degradation. So there is a tradeoff between the degree of aminolysis and the downgrade of mechanical properties. Thus, it was critical to choose the optimal conditions to perform the aminolysis reactions and to introduce free amino groups without significant expense on the mechanical properties. To that end, a preliminary assay was conducted in order to choose the parameters of the aminolysis reaction and specifically the reaction time. The concentration of the diamine solution was kept constant and the temperature of the process was fixed at $58{ }^{\circ} \mathrm{C}$ in order to study the influence of the reaction time. The reaction time was 90,900, and $9000 \mathrm{~s}$. Longer times led to significant weight loss, degradation of PLA, and severe reduction of the mechanical properties. FTIR was used as a tool to assess the efficiency of the aminolysis reaction on the introduction of amino groups and gel permeation chromatography (GPC) was performed to evaluate the molecular weight distribution after the reaction. The results in terms of $\bar{M}_{\mathrm{w}}$ and $\bar{M}_{\mathrm{n}}$ and polydispersity index (PDI) obtained from GPC are reported in Table 1 . The reduction of $\bar{M}_{\mathrm{w}}$ with aminolysis time was confirmed and a significant increase of PDI for the reaction performed at $90 \mathrm{~s}$ is observed. In that way, a milder condition was chosen for the functionalization of the PLA membranes through aminolysis reactions at $58^{\circ} \mathrm{C}$ for $90 \mathrm{~s}$.

In Figure 1, the ATR-FTIR spectra of pure PLA, aminolyzed PLA (amPLA) and amPLA + TEOS/GPTMS 1:1 are presented. The characteristic bands of PLA structure could be identified in the obtained spectrum of pure PLA film: ${ }^{[25,26]}$ The $-\mathrm{C}=\mathrm{O}$ carbonyl stretch at $1748 \mathrm{~cm}^{-1}$, the $-\mathrm{CH}_{3}$ bend at 1452 
Table 1. $\bar{M}_{\mathrm{w}} \bar{M}_{\mathrm{n}}$ and polydispersity index (PDI) obtained from GPC for aminolyzed PLA for various times.

\begin{tabular}{lccc} 
& \multicolumn{3}{c}{ GPC } \\
\cline { 2 - 4 } Aminolysis time [s] & $\overline{\boldsymbol{M}}_{\mathbf{w}}$ & $\boldsymbol{M}_{\mathbf{v}}$ & PDI \\
\hline 0 & 340000 & 210000 & 1.62 \\
90 & 240000 & 70000 & 3.43 \\
900 & 130000 & 70000 & 1.81 \\
9000 & 44000 & 25000 & 1.74
\end{tabular}

$\mathrm{cm}^{-1}$, the $-\mathrm{CH}-$ deformation at 1380 and $1359 \mathrm{~cm}^{-1}$, the $-\mathrm{C}-\mathrm{O}-$ stretch at 1180,1128 , and $1078 \mathrm{~cm}^{-1}$ while the band appearing at 871 and $756 \mathrm{~cm}^{-1}$, can be attributed to the amorphous and crystalline phases of PLA, respectively. Apart from those characteristic bands, the spectrum of the amPLA film presents two additional peaks located at 1648 and $1548 \mathrm{~cm}^{-1}$. The latter peaks correspond to amide I and amide II bands, respectively, and are used as a confirmation of the presence of amino groups in aminolyzed polyesters. ${ }^{[27,28]}$ Thus, the appearance of the above bands provides a clear proof of the introduction of amino groups on the surface of PLA by the reaction employed using diamine. Furthermore, the decrease of amide I in the spectrum of PLA+TEOS/GPTMS 1:1 implies that the functional groups are consumed providing an indication that the introduced amino groups have reacted with the epoxy groups of GPTMS.

\subsection{Morphology}

The morphology of the cross-section of the membranes was studied by SEM. Representative micrographs are presented

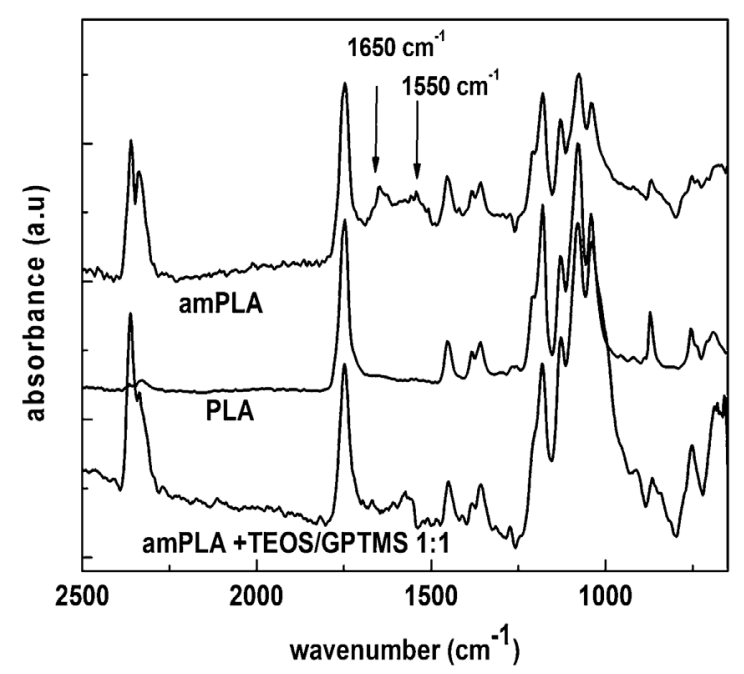

Figure 1. FTIR spectra of pure PLA, amPLA, and amPLA + TEOS/ GPTMS 1:1. in Figure 2 showing the interconnected porous structure of the membranes with a pore size around $10 \mu \mathrm{m}$. The porosity of the initial PLA membranes is dictated by the conditions selected for the freeze-extraction, namely the concentration of PLA in dioxane and the protocol followed for the freezing of PLA/dioxane solution. ${ }^{[29]}$ The above parameters provide a versatile tool for adjusting the pore size and the overall porosity of the prepared membranes. In the present study, a concentration of $10 \%$ PLA in dioxane and the rapid freezing with liquid nitrogen yielded the porous structure shown on SEM micrographs with a porosity of $77 \%$ as evaluated by gravimetric techniques. It is worth noting that the combination of complementary techniques (e.g., particle leaching) could lead to structures characterized by macroporosity giving a high versatility for the control of pore architecture to meet the needs of the application envisaged.

The membranes after the functionalization with amino groups show the same morphology compared to unfunctionalized membranes (Figure 2a,b). The above structure of well-interconnected pores is retained also after the completion of sol-gel reactions inside the pores of the membranes. The porosity of the scaffolds is reduced in the hybrid membranes after performing the sol-gel reactions, as expected. The porosity obtained varies between 66 and $75 \%$ depending on the ratio of the silica precursors TEOS/GPTMS and is reported in Table 2. The lower porosity of $66 \%$ is obtained when only TEOS is used as the precursor of the silica phase.

The acidic conditions used for performing the sol-gel reactions resulted in the formation of continuous silica phase covering the walls of PLA pores. It is well established that low $\mathrm{pH}$ values lead to continuous silica phase while basic conditions yield to the synthesis of microparticles and more branched species. ${ }^{[30,31]}$ The proposed morphology is proved by the SEM micrographs showing the residue after pyrolysis at $850^{\circ} \mathrm{C}$ (Figure 2f). It should be noted that no residue was observed after pyrolysis of pure PLA and amPLA membranes. The above observation combined with the SEM analysis of the residues of hybrid materials after pyrolysis provide an indirect but convenient way to study the structure of the inorganic component. After pyrolysis, the organic phase is removed and only the inorganic component of the hybrid materials is left revealing the structure of the inorganic phase composed of silica. The hypothesis of the preparation of a two co-continuous phase composite with a high porosity is clearly evidenced from the above analysis.

\subsection{Thermogravimetric Analysis}

The TGA thermograms and the corresponding derivative curves of pure PLA, amPLA, amPLA + TEOS, and amPLA +

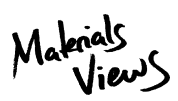

www.MaterialsViews.com
Macromol. Biosci. 2014, DOI: 10.1002/mabi.201400339

(C) 2014 WILEY-VCH Verlag GmbH \& Co. KGaA, Weinheim

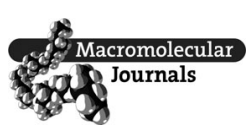

Early View Publication; these are NOT the final page numbers, use DOI for citation !! 

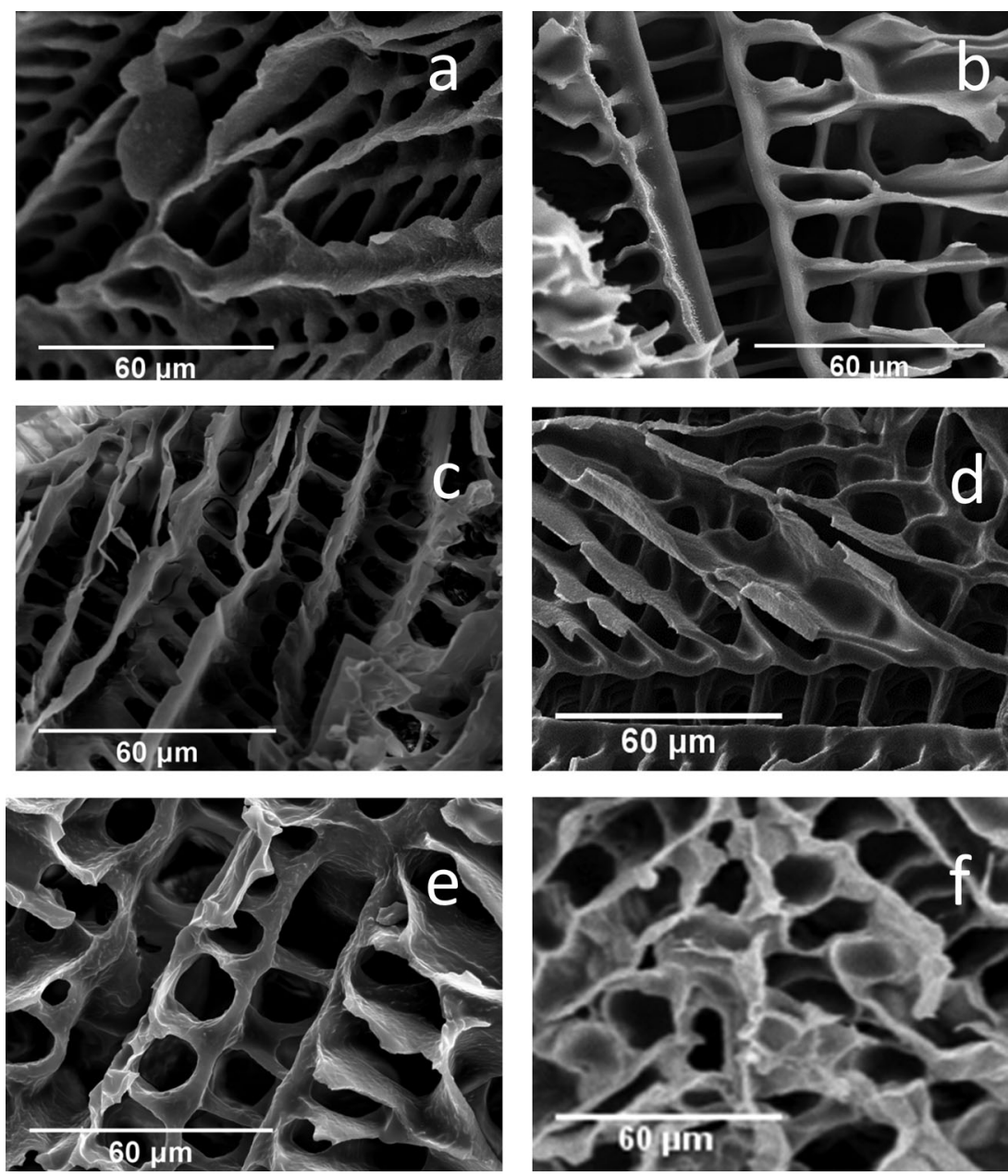

Figure 2. SEM micrographs; a) pure PLA, b) amPLA, c) amPLA + TEOS/GPTMS 1:0.1, d) amPLA + TEOS/GPTMS 1:0.5, e) amPLA + TEOS/GPTMS 1:1, and f) pyrolysis residue of amPLA + TEOS/GPTMS 1:0.5.

Table 2. Porosity of the membranes and residue after pyrolysis at $850^{\circ} \mathrm{C}$.

\begin{tabular}{lcc} 
Sample & $\begin{array}{c}\text { Porosity } \\
\text { [\%] }\end{array}$ & $\begin{array}{c}\text { Residue after } \\
\text { pyrolysis [\%] }\end{array}$ \\
\hline amPLA & 77 & - \\
amPLA + TEOS & 66 & 26 \\
amPLA + TEOS/GPTMS 1:0.05 & 70 & 16 \\
amPLA + TEOS/GPTMS 1:0.1 & 75 & 14 \\
amPLA + TEOS/GPTMS 1:0.2 & 68 & 16 \\
amPLA + TEOS/GPTMS 1:0.5 & 67 & 12 \\
amPLA + TEOS/GPTMS 1:1 & 68 & 14
\end{tabular}

TEOS/GPTMS membranes prepared with various TEOS/ GPTMS ratios are presented in Figure 3. An initial weight loss at around $100^{\circ} \mathrm{C}$ could be seen only for the PLA + TEOS membrane. The above weight loss is associated with the evaporation of water bound or trapped in the membranes. It is well known that PLA is a highly hydrophobic polymer as will be seen later in the discussion of water sorption measurements. Silica presents a hydrophilic character due to the remaining silanol groups ( $\mathrm{Si}-\mathrm{OH}$ ), which are always present in its surface. Previous studies have shown that the binding sites of silica prepared by sol-gel are already occupied by water molecules at a relative humidity level of $20 \%$ with a water content around $10 \%$. ${ }^{[32]}$

By increasing the temperature, the thermal degradation of the organic part takes place. Pristine PLA and amPLA present similar profiles of one step degradation within a narrow temperature range, which is depicted by only one peak in the DTA signal located around $350^{\circ} \mathrm{C}$. The onset decomposition temperature $\left(T_{\mathrm{d}}\right)$ of aminolyzed PLA is slightly lower compared to pure PLA that could be justified by the slight decrease of molecular weight ${ }^{[33]}$ upon aminolysis as shown earlier. The decomposition temperature of the composites shifts to higher temperatures except for the amPLA + TEOS/GPTMS 1:1 membrane. The profile of the samples containing silica presents also one step degradation apart from the amPLA TEOS/GPTMS 1:1 membrane, which shows two peaks at 328 and at $400^{\circ} \mathrm{C}$. Interestingly, the peak at higher temperature is shifted to lower temperatures compared to the one that correspond to TEOS/GPTMS 1:1 as shown in Figure 3c.

\subsection{Thermal Properties}

Figure 4 shows the DSC thermograms of the membranes recorded during the first and second heating scan with a heating rate of $10^{\circ} \mathrm{C}$. Pure PLA and amPLA present only the endothermic peak corresponding to the melting of PLA while the glass transition is barely observable. The same behavior holds also for the composites with silica expect for the one where silica was produced using only TEOS. The melting peak recorded is attributed to the formation of crystallites during the step of the preparation procedure where the samples stayed at $90^{\circ} \mathrm{C}$ for $24 \mathrm{~h}$. The above conditions served as an annealing process allowing the formation of crystallites. 
a)

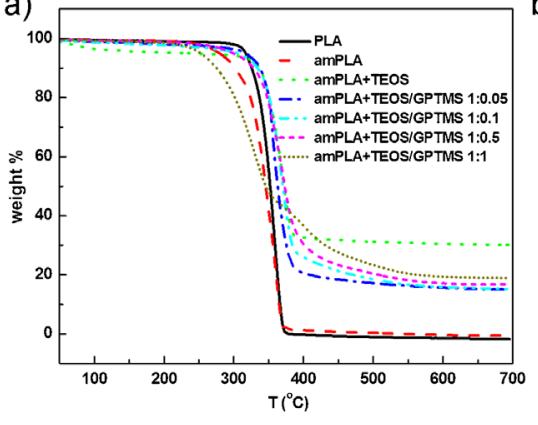

b)

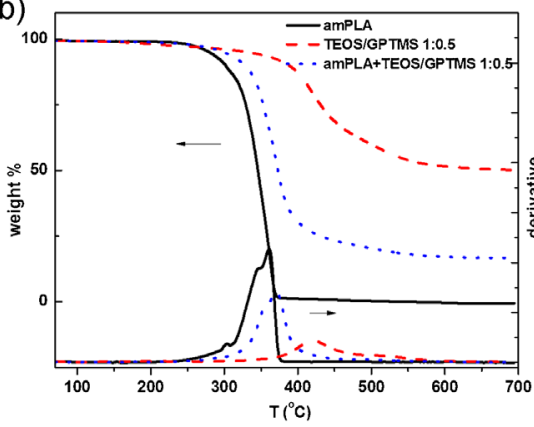

c)

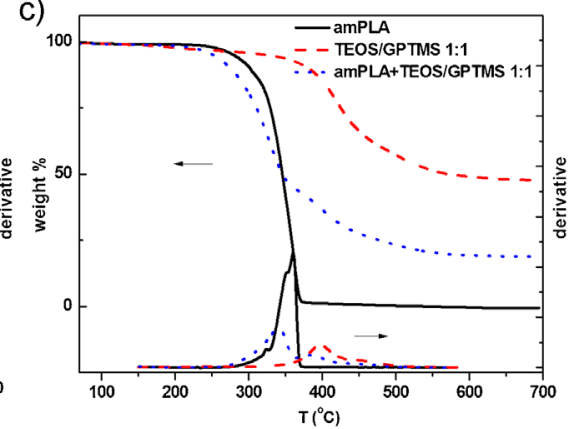

Figure 3. TGA thermograms of PLA, amPLA, and amPLA + TEOS/GPTMS.

The glass transition temperature $\left(T_{\mathrm{g}}\right)$, the melting temperature $\left(T_{m}\right)$, and the increment of the heat capacity $\left(\Delta C_{\mathrm{p}}\right)$ at glass transition of the various samples are also reported in Table 3 . It is noted that all the values of $\Delta C_{p}$ presented are normalized to the amorphous part of the samples by taking into account the organic part and the crystalline fraction of PLA. The crystalline fraction, $\chi_{c}$, was estimated by using the relation $\chi_{\mathrm{c}}=\Delta H / \Delta H_{\mathrm{o}}$, where $\Delta H$ is the measured enthalpy of fusion of the sample and $\Delta H_{\mathrm{o}}$ is the enthalpy of fusion of the completely crystalline material. Taking into account the $\Delta H$ of $100 \%$ of PLA as $93.1 \mathrm{~J} \mathrm{~g}^{-1},{ }^{[34]}$ the values of $x_{\mathrm{c}}$ were calculated and reported in Table 3.

The thermograms corresponding to the second heating scan and after erasing the thermal history present different thermal characteristics. It has been shown in previous works that the formation of crystallites in PLA is strongly dependent on the cooling rate used after the melting and that cooling rates higher than $5^{\circ} \mathrm{C}$ lead to an amorphous material. ${ }^{[34,35]}$ After using a cooling rate of $10^{\circ} \mathrm{C}$ in the present case a clear glass transition is observed for all the samples in the second heating scan while the parameters calculated from the analysis are reported in Table 3 . The $T_{\mathrm{g}}$ of PLA remains unaffected and around $60^{\circ} \mathrm{C}$ apart from the amPLA TEOS/GPTMS 1:1, which presents a broader glass transition with a $T_{\mathrm{g}}$ at $48^{\circ} \mathrm{C}$. Additionally, all the samples except for PLA and PLA + TEOS present an exothermic peak during heating, the so-called cold crystallization and its characteristic temperature $\left(T_{\mathrm{cc}}\right)$ is reported in Table 3. As temperature increases, the crystallites formed during the latter process are melted to give the recorded melting peak. The different behavior between the composite with only TEOS and those that incorporate GPTMS probes the influence of the latter on the segmental dynamics of PLA. Interestingly there is a trend of lowering of the cold crystallization temperature upon increasing the GPTMS content.

Moreover, from the data presented in Figure 4, the integration of the DSC trace covering both crystallization and melting peaks gives a negligible enthalpy, characteristic of a nearly amorphous material ${ }^{[34]}$ as can been seen in Table 3. Another alteration in the melting of PLA is the slight decrease of the melting temperature especially for the membranes with higher amount of GPTMS. This fact is due to the lower crystallization temperature in the cold crystallization peak in these samples that produce smaller crystals.

\subsection{Water Sorption Measurements}

Figure 5 a shows the equilibrium water sorption isotherms up to water activity, $\alpha_{\mathrm{w}}$, of 0.95 at $25^{\circ} \mathrm{C}$ for pure PLA,
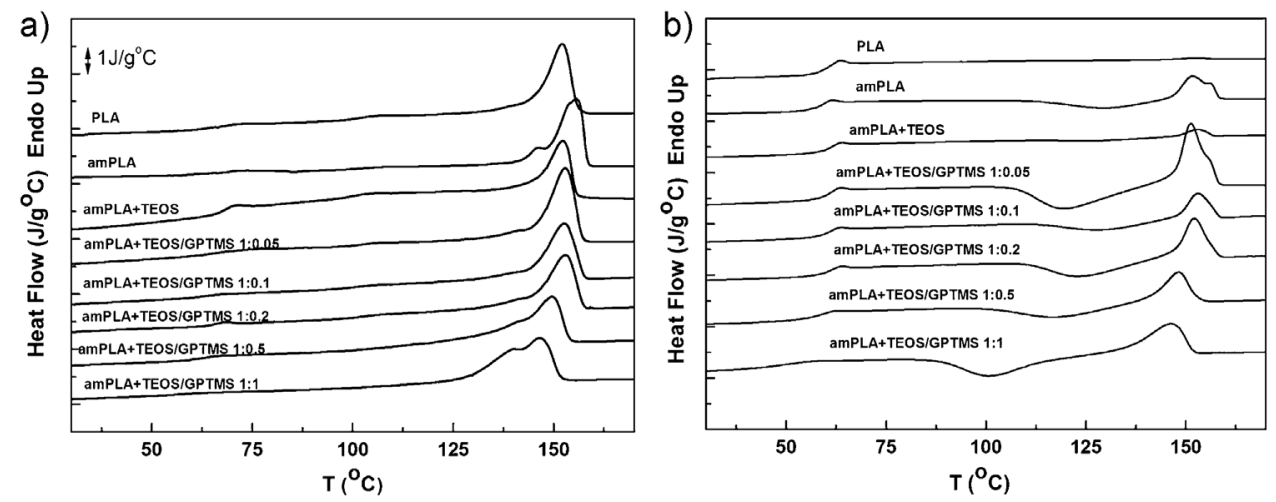

Figure 4. DSC thermograms recorded during first (a) and second (b) heating scan.

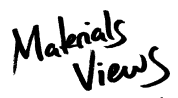

www.MaterialsViews.com
Macromol. Biosci. 2014, DOI: 10.1002/mabi.201400339

(C) 2014 WILEY-VCH Verlag GmbH \& Co. KGaA, Weinheim

Early View Publication; these are NOT the final page numbers, use DOI for citation !! 


\begin{tabular}{|c|c|c|c|c|c|c|c|c|c|c|c|}
\hline \multirow[b]{2}{*}{ sample } & \multicolumn{5}{|c|}{ First heat } & \multicolumn{6}{|c|}{ Second heat } \\
\hline & $T_{\mathrm{g}}\left[{ }^{\circ} \mathrm{C}\right]$ & $\begin{array}{c}\Delta C_{\mathrm{p}}{ }^{*} \\
{\left[\mathrm{~J} \mathrm{~g}^{-1}{ }^{\circ} \mathrm{C}^{-1}\right]}\end{array}$ & $T_{\mathrm{m}}\left[{ }^{\circ} \mathrm{C}\right]$ & $\begin{array}{c}\Delta H \\
{\left[\mathrm{~J} \mathrm{~g}^{-1}\right]}\end{array}$ & $x_{c}[\%]$ & $T_{\mathrm{g}}\left[{ }^{\circ} \mathrm{C}\right]$ & $\begin{array}{c}\Delta C_{\mathrm{p}}{ }^{*} \\
{\left[\mathrm{~J} \mathrm{~g}^{-1}{ }^{\circ} \mathrm{C}^{-1}\right]}\end{array}$ & $T_{\text {cc }}\left[{ }^{\circ} \mathrm{C}\right]$ & $T_{\mathrm{m}}\left[{ }^{\circ} \mathrm{C}\right]$ & $\begin{array}{c}\Delta H \\
{\left[\mathrm{~J} \mathrm{~g}^{-1}\right]}\end{array}$ & $x_{\mathrm{c}}[\%]$ \\
\hline PLA & 63 & 0.10 & 155 & 22.0 & 23.7 & 60.0 & 0.6 & - & 152 & 0.3 & 0.0 \\
\hline amPLA & 61 & 0.11 & 156 & 32.0 & 34.4 & 58.5 & 0.6 & 129.3 & 152 (157) & 1.3 & 1.4 \\
\hline amPLA-TEOS & 69 & 0.48 & 152 & 13.0 & 20.3 & 60.8 & 0.6 & - & 153 & 1.6 & 2.5 \\
\hline $\begin{array}{l}\text { amPLA + TEOS/ } \\
\text { GPTMS 1:0.05 }\end{array}$ & 67 & 0.12 & 153 & 16.0 & 20.2 & 60.1 & 0.5 & 119.7 & $151(156)$ & 3.0 & 3.8 \\
\hline $\begin{array}{l}\text { amPLA + TEOS/ } \\
\text { GPTMS 1:0.1 }\end{array}$ & 63 & 0.15 & 152 & 17.0 & 21.5 & 58.1 & 0.4 & 128.0 & 153 & 0.0 & 0.0 \\
\hline $\begin{array}{l}\text { amPLA + TEOS/ } \\
\text { GPTMS 1:0.2 }\end{array}$ & 65 & 0.12 & 153 & 20.0 & 25.0 & 59.9 & 0.4 & 123.3 & 152 & 1.0 & 1.3 \\
\hline $\begin{array}{l}\text { amPLA + TEOS/ } \\
\text { GPTMS 1:0.5 }\end{array}$ & 63 & 0.14 & 150 & 22.0 & 28.5 & 60.3 & 0.3 & 116.7 & 148 & 5.7 & 7.4 \\
\hline $\begin{array}{l}\text { amPLA + TEOS/ } \\
\text { GPTMS 1:1 }\end{array}$ & 55 & 0.10 & 139 (147) & 25.0 & 33.2 & 48.5 & 0.4 & 100.7 & 146 & 1.7 & 2.3 \\
\hline
\end{tabular}

amPLA + TEOS/GPTMS 1:0.05, amPLA + TEOS/GPTMS 1:0.5 as well as for bulk TEOS/GPTMS 1:0.05 and TEOS/GPTMS 1:0.5. Firstly, the hydrophobic character of pure PLA is confirmed as the weight increase due to water adsorption reaches only $0.9 \%$ for the highest water activity. It should be kept in mind that PLA is in the glassy state at room temperature. An almost linear increase of wt\% versus $\alpha_{\mathrm{w}}$ is obtained with a slight upturn for the higher water activities. On the contrary, the equilibrium sorption isotherm of bulk TEOS/GPTMS 1:0.05 presents a different behavior with a high increase of water increase at low $\alpha_{\mathrm{w}}$ followed by a linear increase for higher $\alpha_{\mathrm{w}}$. The above behavior is characteristic of a Type I in the Brunauer classification. $^{[36]}$ Type I also referred as Langmuir type sorption isotherms are characterized by their approach to a limiting value of adsorption, and usually describe adsorption onto microporous adsorbents in form of a monolayer, with strong sorbent-substrate interaction. The bulk sample obtained from TEOS/GPTMS 1:0.5 also present a distinct behavior that could be categorized in the Type III in the Brunauer classification. This class of isotherms describes adsorption onto adsorbents with weak adsorbate-adsorbent interactions. As seen on Figure $5 \mathrm{a}$, an initial linear region for water activity up to 0.6 is observed, followed by a departure from linear behavior for $\alpha_{\mathrm{w}}>0.6$, which is typical for hydrogels and is explained in terms of clustering of water molecules. As concerns the hybrid membranes the sorption profile depends on the ratio of TEOS/GPTMS. From the above isotherms, it is clear that water sorption is greatly influenced by the characteristic sorption behavior of the
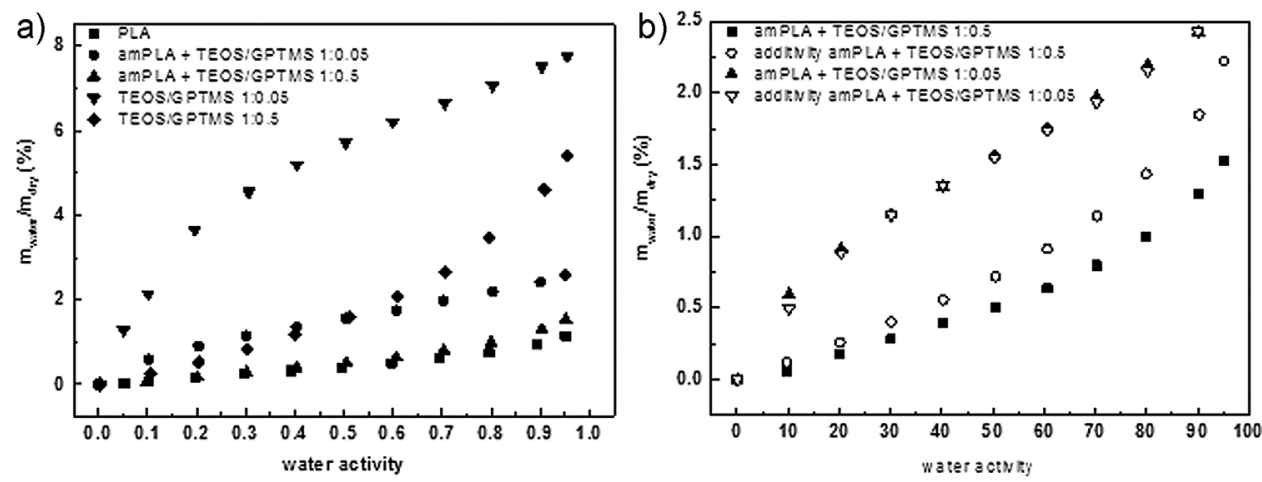

Figure 5. Equilibrium sorption isotherms of pure PLA and PLA + TEOS/GPTMS composites measured at room temperature. 
introduced inorganic phase of the hybrids. To further analyze the contribution of the inorganic phase by taking also into account the relative percentage in the final hybrid the Figure $5 \mathrm{~b}$ is presented. In the latter, the measured sorption isotherms of the hybrids are given together with the theoretical isotherms calculated as a linear combination of the data for the pure components, that is, by assuming additivity. The curve corresponding to amPLA + TEOS/ GPTMS 1:0.05 constructed using the additivity hypothesis coincides with the experimental sorption isotherm. The microporous nature of the absorbent, in this case the silica that covers the walls of the pores of PLA membranes, is clearly evidenced by the form of the sorption isotherm. On the contrary, the measured isotherm and the theoretical one assuming additivity of amPLA + TEOS/GPTMS 1:0.5 present different behavior. These isotherms correspond to absorbance by bulk polymers without indications of the presence of microporosity. Furthermore, a difference is observed when comparing the measured isotherm with the theoretical one with a lower water uptake observed for the former. This implies that fewer water adsorption sites are present after the introduction of TEOS/GPTMS compared to the hypothetical case that the two components would adsorb water independently. The above behavior could be attributed to the higher affinity of the reinforcement to the PLA thus providing an indirect indication of the interaction between the introduced phase and PLA.

\subsection{Mechanical Properties}

The mechanical properties of the membranes were studied by dynamic mechanical analysis. The steps appeared in the graphs of the dynamic storage modulus $\left(E^{\prime}\right)$ in Figure 6a and the peaks in the graphs of tangent delta $(\tan \delta)$ in Figure $6 \mathrm{~b}$ correspond to the glass transition of PLA. A slight increase of the glass transition temperature is observed for the PLA + TEOS and for the amPLA + TEOS/GPTMS 1:0.05 in accordance with the DSC results obtained during the first heating scan. On the contrary, a slight decrease of $T_{\mathrm{g}}$ is observed for the hybrid membranes with higher GPTMS content. Furthermore, the elastic modulus of the hybrid composites also depends on the TEOS/GPTMS ratio in both, the glassy and the rubber-like state of the polymer. Thus, tuning the TEOS/GPTMS ratio we may modulate the mechanical response of the material. More specifically, an increase of $E^{\prime}$ in the glassy and rubbery state of the hybrids, as compared to neat PLA, is observed, except for the composite with TEOS/GPTMS 1:1. We recall, that a decrease of glass transition temperature $T_{\mathrm{g}}$ for the composites with the highest TEOS/GPTMS ratio (1:1) has been observed, while an increase of $T_{\mathrm{g}}$ for the composites with only TEOS and TEOS/GPTMS 0.05 has been observed. Therefore, our results may suggest that the TEOS/GPTMS ratio of 1:0.5 can lead to the optimum composition for improving the mechanical properties of the sample without altering the $T_{\mathrm{g}}$. Interestingly, the main relaxation process of PLA broadens with the addition of the coating when it contains GPTMS what means that their organic side groups penetrate in the PLA walls deep enough to modify the conformational motions of PLA chains.

\subsection{Osteogenic Differentiation Study}

MSCs were seeded upon support materials in a twodimensional monolayer culture at a density of 10000 cells per sample. DNA content of attached mesenchymal stem cells was determined with Picrogreen ${ }^{\mathbb{R}}$ assay. As can be seen in Table 4, all the samples showed a similar cell seeding efficiency and proliferate through the time except for amPLA + TEOS:GPTMS 1:0.05 sample, which showed the lowest DNA content and did not show cell proliferation (Figure 7).

There was a concern that the direct contact of the cells with unreacted epoxy groups exhibited at the surface of the supports could have a cytotoxic effect due to the reaction of these reactive groups with amine groups in proteins of cell membranes. Indirect cytotoxicity studies (ISO 10993-5)
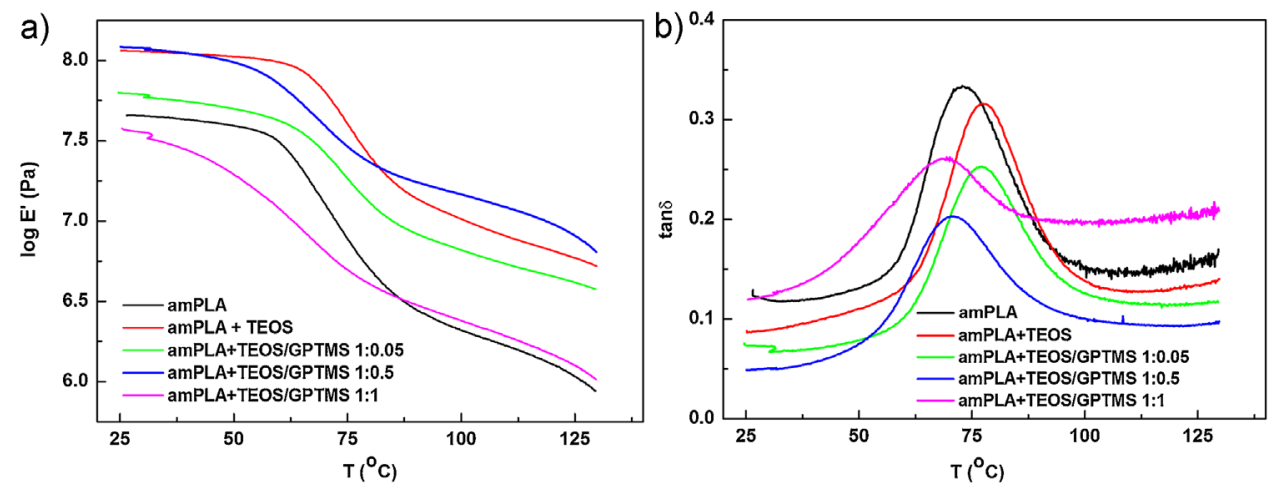

Figure 6. Storage modulus (a) and $\tan \delta(b)$ for amPLA and amPLA + TEOS/GPTMS hybrids obtained by DMA.

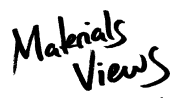

www.MaterialsViews.com
Macromol. Biosci. 2014, DOI: 10.1002/mabi.201400339

(C) 2014 WILEY-VCH Verlag GmbH \& Co. KGaA, Weinheim

Early View Publication; these are NOT the final page numbers, use DOI for citation !! 
Table 4. Percentage of seeding efficiency calculated as ((ng $\mathrm{DNA}_{\text {sample, } 1 \mathrm{~d}} \times \mathrm{ng}$ DNA cell $/$ /density of seeding) $\times 100$, for all materials.

Sample Seeding efficiency [\%]

$\begin{array}{ll}\text { PLA } & 41.30 \pm 5.64 \\ \text { amPLA } & 40.46 \pm 9.50 \\ \text { amPLA + TEOS } & 34.67 \pm 9.72 \\ \text { amPLA + TEOS:GPTMS 1:0.05 } & 46.14 \pm 18.20 \\ \text { Control } & 31.38 \pm 1.76\end{array}$

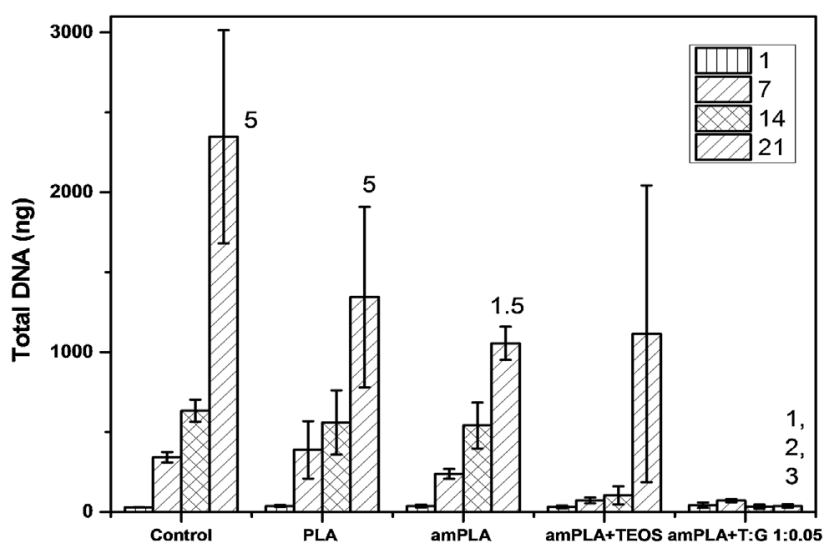

Figure 7. Quantification of total DNA at 1, 7, 14, and $21 \mathrm{~d}$ for different materials. Significance of $p$-value $<0.05$ compared to similar group is signaled as 1 (Control), 2 (PLA), 3 (amPLA), 4 (amPLA + TEOS), 5 (amPLA + TEOS:GPTMS 1:0.05) for each group at the same time.

were performed previously in films of polysaccharide containing GPTMS and TEOS. ${ }^{[37]}$ Briefly, different films with various GPTMS:TEOS molar ratios were studied immersing them in culture media for $24 \mathrm{~h}$. This culture media with the by-products of the materials was used to feed a $24 \mathrm{~h}$ fibroblast L292 culture in a 96-well-multiplate. After $24 \mathrm{~h}$, the viability of cells was tested by means of MTT assay. The results showed that the presence of GPTMS did not show any cytotoxic effect, therefore, it was concluded that GPTMS do not liberate any toxic by-product. ${ }^{\left[{ }^{37]}\right.}$ The above findings are also supported by studies on hybrid materials incorporating GPTMS, which exhibited excellent levels of cytocompatibility with human MG63 osteosarcoma cells, and human bone marrow osteoblasts. ${ }^{[38,39]}$ However, in spite that cell numbers on amPLA + TEOS:GPTMS supports are much smaller than in PLA or amPLA + TEOS supports, osteoblastic differentiation of MSCs on GPTMS containing supports is significantly improved with respect to pure PLA supports.

PLA TEOS membranes had a proliferation profile smaller than PLA membranes but higher than GPTMS containing membranes.

Osteogenic differentiation was evaluated by collagen quantification, determination of alkaline phosphatase activity and histochemistry. Collagen content was determined by the oxidation of hydroxyproline, which is an imino acid typical of collagen. Briefly, the hydroxyproline contains a pyrrolidine ring that can oxidize into a pyrrole ring, which can be determined by a reaction using Ehrlich's reagent, resulting in a quinoid compound that is colored. The quantification of collagen via hydroxylation of hydroxyproline is shown in Figure 8a. As expected, the major amount of collagen was at $21 \mathrm{~d}$ in all materials, when cells have been deposited the extracellular matrix. It is interesting to note that in amPLA + TEOS membranes the production of collagen starts at $7 \mathrm{~d}$ with the highest amount of collagen. Collagen normalized respect to DNA content (Figure 8b) showed similar values for all nonhybrid samples. Hybrid materials showed the highest normalized collagen content pointing to cells with more synthetic capacity compared to cells seeded on naked materials.
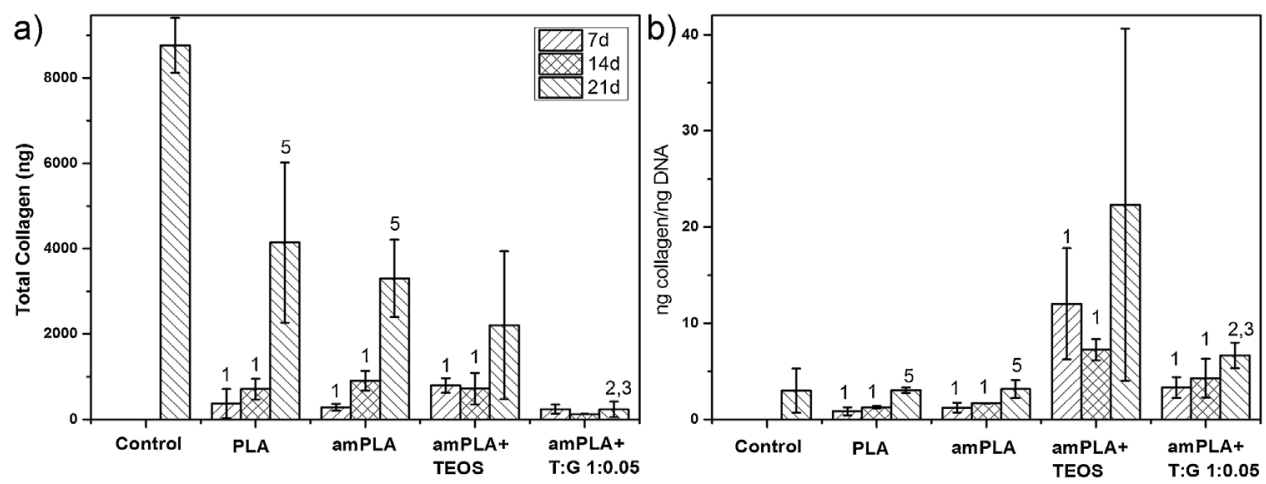

Figure 8. a) Quantification of collagen by means of hydroxylation of hydroxyproline for three different times (7, 14, and $21 \mathrm{~d})$ in different materials; b) representation of the collagen normalized respect to DNA in each sample. Significance of $p$-value $<0.05$ compared to similar group is signaled as 1 (Control), 2 (PLA), 3 (amPLA), 4 (amPLA + TEOS), 5 (amPLA + TEOS:GPTMS 1:0.05) for each group at the same time. 


\section{Control}

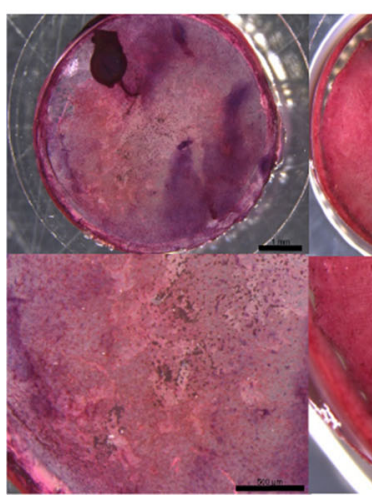

PLA

amPLA

amPLA+TEOS

amPLA+T:G 1:0.05

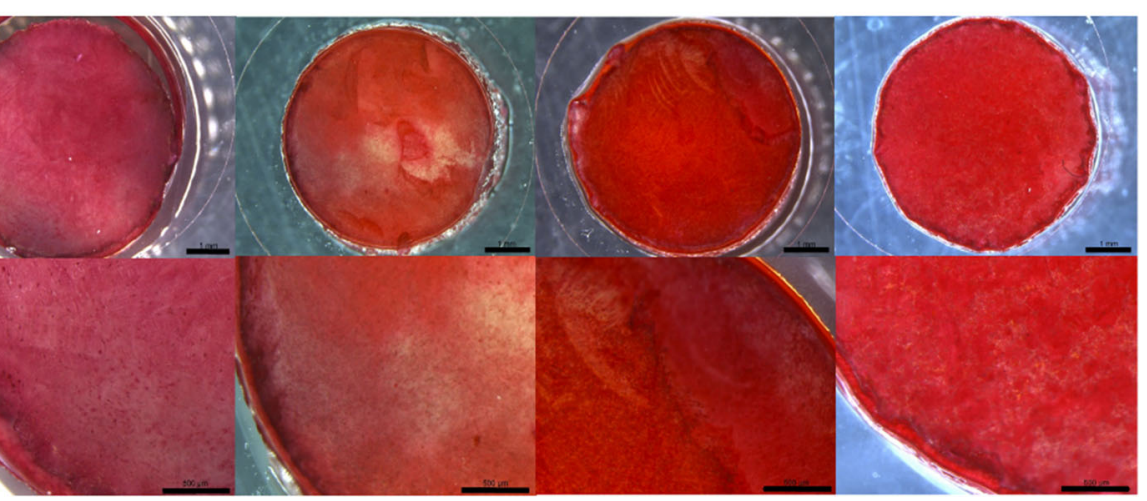

Figure 9. Picrosirius red staining of $21 \mathrm{~d}$ cell seeded materials. Scale bar for the upper picture of each material: $1 \mathrm{~mm}$ and scale bar for the lower picture of each material: $500 \mu \mathrm{m}$.

Histological staining for collagen was performed with picrosirius red. Sirius red molecule binds to triple helical collagen and does not bind to degraded collagen or other proteins without the typical triple helical conformation of collagen. Figure 9 shows the images taken with a stereoscopic microscope for the picrosirius red staining, the blank was performed with each material stained in their acellular form. The typical red-orange staining was seen for amPLA and hybrid membranes showing amPLA + TEOS the most intense stain. The control did not show presence of collagen staining. It is worth noting the intense coloration of amPLA+ TEOS:GPTMS support in spite to the small number of cells.

Calcium phosphate is the most abundant mineral compound on bone extracellular matrix. The presence of calcium was detected through alizarin red staining (Figure 10). Alizarin red $S$ is an anthraquinone derivative, which binds to calcium in a chelation process. Figure 10 shows the pictures taken for the calcium staining. In general, there is no presence of calcium aggregates except for amPLA + TEOS:GPTMS 1:0.05 material, which have small calcium-alizarin red S complexes.

When MSCs are cultured in presence of ascorbic acid, $\beta$-glycerol phosphate, and dexamethasone acquire osteoblastic like phenotype with upregulated alkaline phosphatase activity. Therefore, ALP activity was used as a biochemical marker for the osteoblast phenotype and it is presented in Figure 11. amPLA showed the major ALP activity in terms of total product, however GPTMS hybrid membrane present the major normalized ALP activity respect to DNA.

The above results for the evaluation of the osteogenic differentiation, PLA, amPLA, and amPLA + TEOS samples did not show significant differences with respect to the expression of osteogenic markers although amPLA + TEOS show a significantly higher production of extracellular matrix.

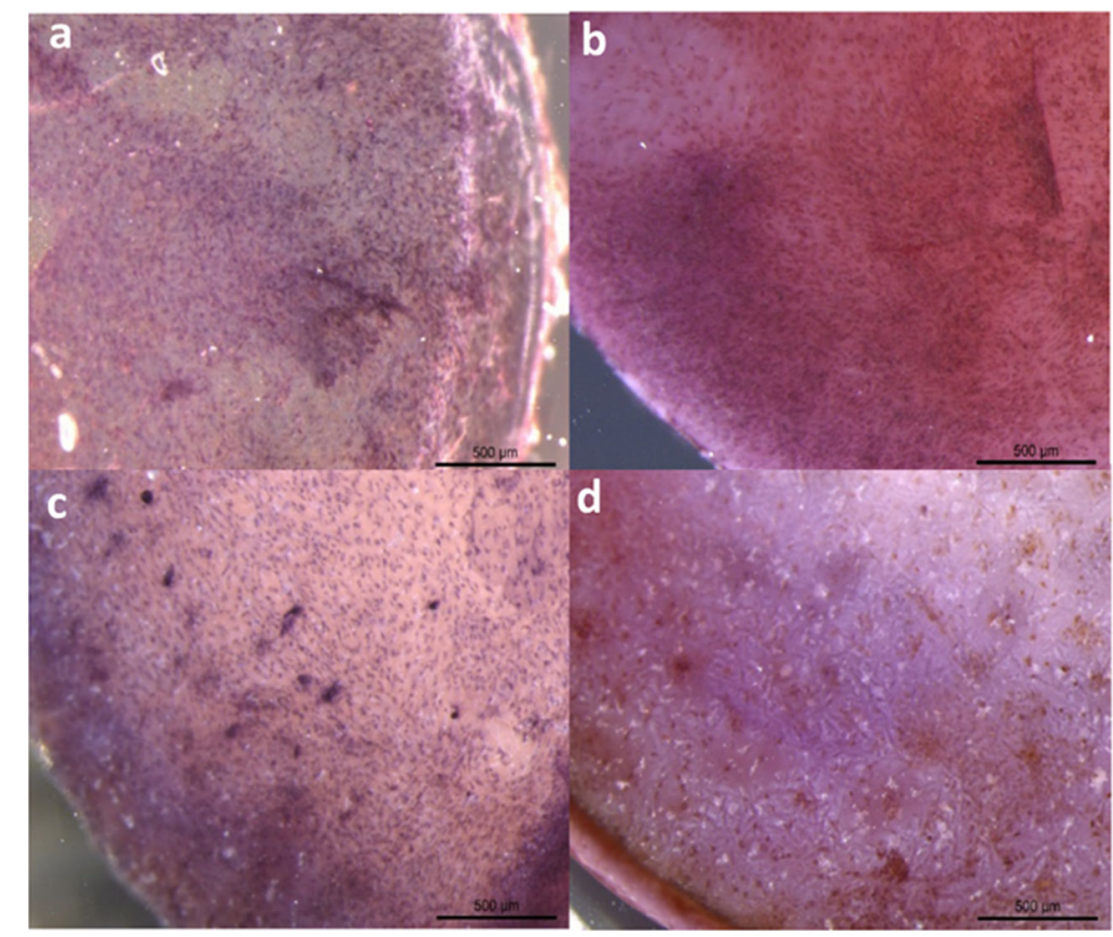

Figure 10. Alizarin RedS staining of $21 \mathrm{~d}$ cell seeded materials. a) Control, b) PLA, c) amPLA + TEOS, and d) amPLA + TEOS:GPTMS 1:0.05. Scale bar: $500 \mu \mathrm{m}$.

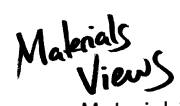

www.MaterialsViews.com
Macromol. Biosci. 2014, DOI: 10.1002/mabi.201400339

(C) 2014 WILEY-VCH Verlag GmbH \& Co. KGaA, Weinheim

Early View Publication; these are NOT the final page numbers, use DOI for citation !! 

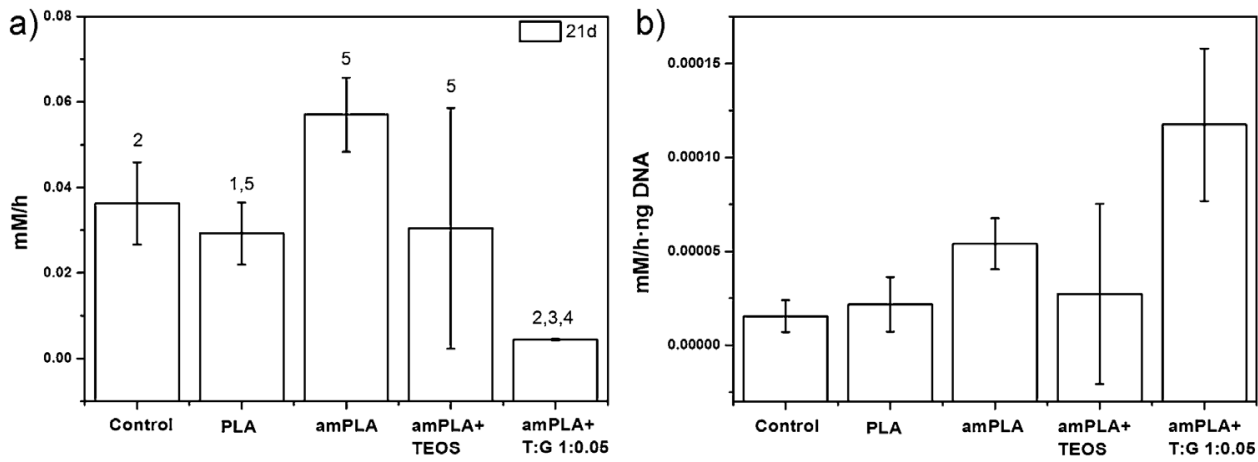

Figure 11. a) Quantification of the ALP activity at $21 \mathrm{~d}$ showed as $\mathrm{mm} p$-nitrophenol per hour, b) representation of the ALP activity normalized to DNA. Significance of $p$-value $<0.05$ compared to similar group is signaled as 1 (Control), 2 (PLA), 3 (amPLA), 4 (amPLA + TEOS), 5 (amPLA + TEOS:GPTMS 1:0.05) for each group at the same time.

GPTMS-coated membranes, which form a very complex network, seem to produce cell death as can be observed at the Figure 7. Nevertheless, it has been shown that the GPTMS-containing membrane present the highest osteoblastic-like phenotype showing high levels of normalized collagen content respect DNA, high collagen staining, some calcium staining, and the highest levels of normalized ALP activity respect DNA. Nevertheless, inactivation of unreacted epoxy groups seems to be a requirement and the follow up of the cytotoxicity of the degradation products during silica network dissolution in biological fluids is necessary.

\section{Conclusion}

Hybrid porous membranes were obtained following a novel strategy for the reinforcement of already prepared porous polymer membranes with silica. Firstly, porous PLA membranes were prepared using freeze extraction techniques. Pore walls were functionalized by an aminolysis treatment to introduce amine groups in their surfaces. In a second stage, silica phase was produced by sol-gel reactions inside the pores using TEOS and GPTMS as the silica precursors and HCL as the acid catalyzer. GPTMS served also as a coupling agent between the organic phase and the silica network. The molar ratio of GPTMS with respect to TEOS in the sol-gel solution was varied between 0.05 and 1. FTIR study revealed the successful introduction of amino groups on PLA surface and provided indications of the bonding with silica phase through GPTMS. SEM showed that the inorganic silica phase forms a co-continuous phase with the polymer phase and that the porous architecture is retained. Furthermore, the coupling between polymer phase and GPTMS was probed by significant changes in segmental dynamics of amorphous phase of PLA as revealed in DSC and dynamic-mechanical experiments. The elastic modulus of the hybrid composites depends on the TEOS/GPTMS ratio both in the glassy and the rubber-like states of the polymer what allows modulating the mechanical response of the material. The shape of the equilibrium sorption isotherms from water vapor sorption measurements provided valuable information regarding the structure of the silica coating of the PLA pores with respect to GPTMS content and supports the hypothesis of the coupling between the inorganic and polymer phase. On the other hand, mesenchymal stem cell in vitro studies were performed showing a scarce initial adhesion in GPTMS containing membranes, however, the few cells attached to the membrane showed the highest osteoblastic-like phenotype in the differentiation study as shows the collagen and ALP activity quantification and also the staining performed.

The presented method of preparation could be applied for the fabrication of macroporous hybrid scaffolds for tissue engineering and extended to incorporate bioactive glass providing thus tailorable ion release for bone bonding applications. Furthermore, the potential use of the obtained porous hybrid structures is not limited to porous membranes for tissue engineering approaches. The proposed strategy is applicable for the preparation of hybrids using various polymers and combined with the great versatility of the sol-gel method through the adjustment of the reaction parameters and the precursors ratio, could allow the modification of the final porosity to meet the specific needs of applications such as ultrafiltration or pervaporation.

Acknowledgements: The research project is implemented within the framework of the Action "Supporting Postdoctoral Researchers" of the Operational Program "Education and Lifelong Learning" (Action's Beneficiary: General Secretariat for Research and Technology), and is co-financed by the European Social Fund (ESF) and the Greek State, Grant No.: NARGEL-PE5(2551). J.R.R. acknowledges funding of his $\mathrm{PhD}$ by the Generalitat Valenciana through VALi+d grant (ACIF/2010/238). J.F.M. thanks the Portuguese Foundation for Science and Technology (FCT) for financial 
support through the PTDC/FIS/115048/2009 project. J.L.G.R. acknowledges the support of the Ministerio de Economía y Competitividad, MINECO, through theMAT2013-46467-C4-1-R project. CIBER-BBN is an initiative funded by the VI National R\&D\&I Plan 2008-2011, Iniciativa Ingenio 2010, Consolider Program, CIBER Actions and financed by the Instituto de Salud Carlos III with the assistance from the European Regional Development Fund.

Received: July 22, 2014; Revised: September 10, 2014; Published online:DOI: 10.1002/mabi.201400339

Keywords: organic-inorganic hybrid composites; porosity; proliferation and osteoblastic differentiation of cells; sol-gel processes; thermomechanical properties

[1] A. Södergård, M. Stolt, "Industrial Production of High Molecular Weight Poly(Lactic Acid)", in Poly(Lactic Acid): Synthesis, Structures, Properties, Processing, and Applications (Eds: L.-T. L. R. Auras, S. E. M. Selke, H. Tsuji), John Wiley \& Sons, Inc., Hoboken, NJ, USA 2010, p. 27.

[2] K. Madhavan Nampoothiri, N. R. Nair, R. P. John, Bioresource Technol. 2010, 101, 8493.

[3] I. Izal, P. Aranda, P. Sanz-Ramos, P. Ripalda, G. Mora, F. Granero-Moltó, H. Deplaine, J. L. Gómez-Ribelles, G. G. Ferrer, V. Acosta, I. Ochoa, J. M. García-Aznar, E. J. Andreu, M. Monleón-Pradas, M. Doblaré, F. Prósper, Knee Surg., Sports Traumatol., Arthrosc. 2013, 21, 1737.

[4] R. A. Jain, Biomaterials 2000, 21, 2475.

[5] J. Yan-Peng, C. Fu-Zhai, Biomed. Mater. 2007, 2, R24.

[6] Y. Zhu, Z. Mao, C. Gao, RSC Adv. 2013, 3, 2509.

[7] L. Yu, K. Dean, L. Li, Prog. Polym. Sci. (Oxford) 2006, 31, 576.

[8] K. Rezwan, O. Z. Chen, J. J. Blaker, A. R. Boccaccini, Biomaterials 2006, 27, 3413.

[9] G. Wei, P. X. Ma, Biomaterials 2004, 25, 4749.

[10] S. S. Ray, K. Yamada, M. Okamoto, K. Ueda, Nano Lett. 2002, 2, 1093.

[11] C.-S. Wu, H.-T. Liao, Polymer 2007, 48, 4449.

[12] S. Verrier, J. J. Blaker, V. Maquet, L. L. Hench, A. R. Boccaccini, Biomaterials 2004, 25, 3013.

[13] G. Z. Papageorgiou, D. S. Achilias, S. Nanaki, T. Beslikas, D. Bikiaris, Thermochim. Acta 2010, 511, 129.

[14] K. Fukushima, D. Tabuani, C. Abbate, M. Arena, P. Rizzarelli, Eur. Polym. J. 2011, 47, 139.

[15] B. Demirdögen, C. E. Plazas Bonilla, S. Trujillo, J. E. Perilla, A. E. Elcin, Y. M. Elcin, J. L. Gómez Ribelles, J. Biomed. Mater. Res. A 2014, 102, 3229.
[16] C. Pandis, S. Madeira, J. Matos, A. Kyritsis, J. F. Mano, J. L. G. Ribelles, Mater. Sci. Eng. C 2014, 42, 553.

[17] M. H. Ho, P. Y. Kuo, H. J. Hsieh, T. Y. Hsien, L. T. Hou, J. Y. Lai, D. M. Wang, Biomaterials 2004, 25, 129.

[18] Y. Gong, Y. Zhu, Y. Liu, Z. Ma, C. Gao, J. Shen, Acta Biomater. 2007, 3, 677.

[19] P. C. Painter, M. M. Coleman, Fundamentals of Polymer Science: An Introductory Text, 2nd Edition Technomic Publishing Co., Lancaster 1997.

[20] L. Liu, M. L. Fishman, K. B. Hicks, C. K. Liu, J. Agric. Food Chem. 2005, 53, 9017.

[21] L. A. Gaona, J. L. Gómez Ribelles, J. E. Perilla, M. Lebourg, Polym. Degrad. Stabil. 2012, 97, 1621

[22] N. Y. Ignat'eva, N. A. Danilov, S. V. Averkiev, M. V. Obrezkova, V. V. Lunin, E. N. Sobol, J. Anal. Chem. 2007, 62, 51.

[23] W. E. Kafienah, T. J. Sims, in Biopolymer Methods in Tissue Engineering, Eds., A. P. Hollander, P. V. Hatton), Humana Press, Totowa, NJ 2004, p. 217.

[24] Y. Zhu, C. Gao, X. Liu, T. He, J. Shen, Tissue Eng. 2004, 10, 53.

[25] G. Kister, G. Cassanas, M. Vert, Polymer 1998, 39, 267.

[26] D. Garlotta, J. Polym. Environ. 2001, 9, 63.

[27] F. Causa, E. Battista, R. Della Moglie, D. Guarnieri, M. Iannone, P. A. Netti, Langmuir 2010, 26, 9875.

[28] S. Yuan, G. Xiong, A. Roguin, C. Choong, Biointerphases 2012, 7, 30.

[29] V. A. Santamaría, H. Deplaine, D. Mariggió, A. R. VillanuevaMolines, J. M. García-Aznar, J. L. G. Ribelles, M. Doblaré, G. G. Ferrer, I. Ochoa, J. Non-Crystal. Solids 2012, 358, 3141.

[30] W. Stöber, A. Fink, E. Bohn, J. Colloid Interface Sci. 1968 , $26,62$.

[31] L. L. Hench, J. K. West, Chem. Rev. 1990, 90, 33.

[32] C. Pandis, A. Spanoudaki, A. Kyritsis, P. Pissis, J. C. R. Hernández, J. L. Gómez Ribelles, M. Monleón Pradas, J. Polym. Sci. B: Polym. Phys. 2011, 49, 657.

[33] F. Carrasco, P. Pagès, J. Gámez-Pérez, O. O. Santana, M. L. Maspoch, Polym. Degrad. Stabil. 2010, 95, 116.

[34] J. F. Mano, J. L. Gómez Ribelles, N. M. Alves, M. Salmerón Sanchez, Polymer 2005, 46, 8258.

[35] Y. Wang, J. L. Gómez Ribelles, M. Salmerón Sánchez, J. F. Mano, Macromolecules 2005, 38, 4712.

[36] S. Brunauer, L. S. Deming, W. E. Deming, E. Teller, J. Am. Chem. Soc. 1940, 62, 1723.

[37] E. Pérez-Román, Bachelor Thesis, Universitat Politècnica de València, 2014.

[38] Y. Shirosaki, K. Tsuru, S. Hayakawa, A. Osaka, M. A. Lopes, J. D. Santos, M. H. Fernandes, Biomaterials 2005, 26, 485.

[39] Y. Shirosaki, M. Hirai, S. Hayakawa, E. Fujii, M. A. Lopes, J. D. Santos, A. Osaka, J. Biomed. Mater. Res. A 2014, in press, DOI: $10.1002 / \mathrm{jbm} . \mathrm{a} .35171$.

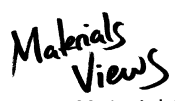

www.MaterialsViews.com
Macromol. Biosci. 2014, DOI: 10.1002/mabi.201400339

(C) 2014 WILEY-VCH Verlag GmbH \& Co. KGaA, Weinheim 